\title{
Some aspects of adaptation and adaptability of barley in European conditions
}

\author{
L. Jestin
}

I.N.R.A. Station d'Amélioration des Plantes, Domaine de Crouelle, F-63039

Clermont-Ferrand Cedex, France

Received 21 January 1985; accepted 5 June 1985

Key-words: barley, adaptability, adaptation, plant development, genotype environment interaction, breeding methods

\section{Summary}

After a review of the different approaches found in the literature concerning problems of adaptation and adaptability of barley, attention is paid to the ecophysiological reasons which may explain the recent extension of winter barley cultivation in NW Europe. A brief account is then given of the cooperative trials carried out in Europe to define better the spring barley varietal adaptability (ESBAN and JESBT trials). Finally a general view of the current statistical procedures proposed in order to analyse adaptability and genotype environment interaction patterns is presented. Some indications are given of the use that the breeder can make of both ecophysiological methodology and statistical models, as far as he is concerned with breeding barley for a wider adaptation.

\section{Introduction}

For many people interested in the barley crop — or any other crop - the questions which can be grouped under the title 'varietal adaptation' are of primary importance. This is true for both the farmer and the crop physiologist. It is also the case for the plant pathologist, but we shall not deal here with the aspects - very important but considered elsewhere - of varietal adaptation to the pathogen $\times$ soil $\times$ climate complex.

Nevertheless varietal adaptation is of continuous concern to the plant breeder. New varieties must be adapted in a fairly large area with some diversity in the environments, and there are now increasingly strong commercial requirements for largescale seed production and marketing. On the other hand, in a given site, the climate will generally vary from year to year, so that any variety needs a reasonable level of homeostasis to give regular yield, and hence to be adapted.

This affords an opportunity to mention the extent to which the late Dr Feekes was concerned with all these facets of varietal adaptation, mainly in wheat, but also 


\section{JESTIN}

in barley as well those of crop physiology (Feekes, 1941) as pathology or breeding questions.

It seems more convenient to concentrate on some points which are either relatively more topical or easier to examplify from the point of view and action of a plant breeder. These will be, after a few comments on terminology and possible approaches:

- aspects of winter barley adaptation

- recent European cooperative work on spring barley adaptation

- finally some remarks about breeding methods for a wide adaptation.

Varietal adaptation or adaptability: terminology, related concepts, different approaches

\section{Terminology}

If we adopt the terminology proposed by Simmonds (1962) and by other authors (Gotoh \& Chang; 1979) the 'adaptability' of a genotype - or population of genotypes - means the extent to which its potential of genetic variation permits, after adequate selection pressure, the obtaining of new genotypes - or populations adapted to a range of different environments. 'Adaptation' is a more static concept: it is the fixed level of fitness of a genotype to a particular environment, i.e. its ability to survive local selective conditions. For a given cultivar in the agricultural context, these conditions should presumably comprise the cultural practices and the requirements of the farmer, and not only the natural agroclimatic or biological parameters.

Simmonds further distinguished specific and general adaptation, but he advised, rightly perhaps as being confusing, against the use of 'adaptability' for the latter meaning. However, it has to be observed that this use is quite common, not surprisingly, because this word conveys immediately the active role played by the plant in adapting itself to changing environmental conditions (e.g. Finlay, 1971; Evans \& Wardlaw, 1976; Kirby \& Appleyard, 1980; Wilson, 1981).

For general adaptation as defined by Simmonds the range of environmental variation which is considered may appear arbitrary. If it is a very wide range - say from NW Europe to sub-arid Mediterranean regions, for example - with contradicting requirements for adaptation at both extremes, a genotype with acceptable general adaptation for this range may not exist. Moreover in a large area like NW Europe most NW European varieties will display some kind of common specific adaptation, when compared to arid zones varieties. In the same way, the range of genetic diversity considered when comparing adaptation of varieties in genotypes $\times$ environments arrays often appears arbitrary also.

One will notice however that adaptation, which reflects varying yields and ecological suitability to different environments, appears closely connected to other concepts such as:

- interaction: genotype $\times$ environment interactions represent the statistical approach (Freeman, 1973; Denis \& Vincourt, 1982).

- genotypic stability, estimated by parameters derived from interactive models 
(Wricke, 1962; Baker, 1969; Eberhart \& Russel, 1966; Becker, 1981; Chowdhury et al., 1982) is used to evaluate the consistency of several genotypic results over environments.

\section{Different approaches}

Multilocation designs provide useful information about varietal adaptation to different environments, but they often fail to explain the reasons for adaptation or inadaptation.

In such multilocation designs, many factors, notably temperature, day-length, solar radiation, are confounded. For a given year $\times$ site situation, this factor combination is unique, or insufficiently reproducible, to permit a reliable cause-response analysis. The major environmental characteristics of soil (type, depth, fertility) and climate (average temperatures, rainfall, etc.) can be recorded, as well as cultivation procedures (data of sowing, density, nitrogen fertilization), and all this at each site. At the end of the experiment, one attempts to use these site parameters to characterize the environment - and to connect them with yield and adaptation properties, or their components - shown by each genotype. This approach is widely employed, especially to make use of large amounts of site $\times$ variety data obtained in series of multi-site experiments, such as registration trials (Reiner, 1975; Finlay \& Wilkinson, 1963; Berbigier et al., 1980).

But there is an alternative, or complementary, approach consisting of systematic factorial experimentation. The aim here is above all a better understanding of the physiological causes of adaptation, to support breeding objectives and to improve cultivation practices. Many studies on cereals including barley have been carried out over the last decades, either purely on the point of view of physiology or agronomy, or for specially designed adaptation studies. Recent reviews by Thorne (1974) and Evans \& Wardlaw (1976) for cereals, and Gallagher, Biscoe \& Dennis-Jones (1983) specifically for barley give a fairly complete synthesis of what has been accomplished in this field.

This ecophysiological approach has firmly established some important points.

1. Considering a growing season at a given site, its soil conditions and expected climate, there is an optimum timing for the plant growth cycle which enables the best possible use of water and nutrient resources while escaping major accidents such as frost damage, lodging, drought, pre-harvest sprouting, etc. (Wilson, 1981). Pests and diseases should also be considered, but have been deliberately neglected in this report.

2. This timing involves an adequate degree of earliness in heading date as well as maturation. Correlatively the plant should have the appropriate architecture as regards tillering, leaf growth, height, components of yield.

3. This development pattern and architecture are largely controlled by temperature and the day-length regime, beside sowing date (Aspinall, 1966; Takahashi \& Yasuda, 1971; De Vos, 1971; De Wit, Van Laar \& Van Keulen, 1979; Yasuda, 1981). Delayed flower initiation due to vernalization requirement prevents frost damage to flowers; with genotypes having a spring habit, a long day requirement for a normal rate of development plays the same role, and prolongs tillering and spikelet pri- 


\section{JESTIN}

mordia production favourably (Kirby, 1969; Kirby \& Appleyard, 1980).

Finally an appropriate maturation period allows the plant to escape both heat and drought hazards due to excessive lateness, or prevents it completing its cycle too early, thereby leaving unexploited a part of the water and nutrient potential offered by the environment.

However some questions are still in discussion. Many of these studies have been carried out in growth chambers where major environment parameters were controlled (Aspinall \& Paleg, 1964; Gustafsson, Ekman \& Dormling, 1974) or semicontrolled glasshouse conditions (De Vos, 1971; Kirby \& Appleyard, 1980). Such conditions do not truly reflect the situation of the field crop, and there are some discrepancies between different authors, due, for instance, to light quality (De Vos, 1971). In addition, it is not always certain that all possible contrasting responses, each represented by one typical genotype, are being considered. For example, in a recent paper by Flood \& Halloran (1984), on the basis of 2 pairs of isogenic wheat genotypes, no interaction was found between vernalization and photoperiod for ear emergence control. Previous work did not always support this evidence (Feekes, 1941; Cooper, 1960; Vincent \& Goujon, 1964; Evans et al., 1975). Finally, when natural or nearly natural conditions are utilized, either in glasshouses or in the field, there are often climatic correlations be.ween factors: between temperature, light and day-length obviously, but also between water stress and nutrient availability. This may render the role of each individual factor difficult to assign safely.

It has been advocated (Donald, 1968) that plant breeders should establish a theoretical plant model called an ideotype, which would be designed by assembling different shape, growth, and development characteristics each recognized as favourable by physiological studies. Such an ideotype should have the best yield potential. The model proposed for wheat was a uniculm plant with a short strong stem, a few small erect leaves, and a large erect ear with awns. The author considered this ideotype suitable for fertile environments with a good water supply. As regards adaptation, this kind of model - then extended to barley - might be less adaptable according to variable water availability, as there would be no regulatory effect by tillering. The model has been discussed by Evans (1975) and Gallagher, Biscoe \& Dennis-Jones (1983), the latter authors pointing out that at least some parts of this model - erect leaves, erect ears - might be unsuitable for particular environments such as dryland areas and windy regions. It has also been emphasized that the ideotype would change with cultivation practices (Evans, 1975), and a material selected according to ideotype would sometimes become outclassed when ready to be released.

Even if the ideotype is not adapted to every situation, it may be useful in proposing new solutions to make further progress in barley breeding.

At the end of a discussion about approaches concerning adaptation, one should not omit the conventional and pragmatic but still efficient approach of many breeders who collect and use a vast amount of empirical observations on the plant, on the environment, on critical limiting defects of available genotypes. 


\section{Winter barley adaptation}

One of the most striking features concerning barley cultivation in Western Europe during the past 15 years concerns the regular increase of winter barley acreage at the expense of spring barley in many countries. This appears clearly when observing the evolution of proportion of winter type in total acreage for most of the important barley producers among in member countries of EBC (see Table 1). The main reason for this change is related to the adaptation problem: in fact with the varieties presently available, winter barley often yields more than spring barley, for example 10-20 \% more in several French regions. Over a large area such as Europe it may be hazardous to propose a single explanation. But often it is not possible to sow spring barley at the right date, because of wheather conditions, or conversely there is a dry period in March. As a consequence, crop establishment is delayed, and active growth may proceed at a mild temperature with relatively long day-length. This tends to accelerate the development, and often the grain yield is considerably lower with late sowing. In this situation also, the plants suffer frequently from water deficit during the grain filling period, or even earlier. This can be illustrated by the results of an experiment at three sites with three varieties, carried out in 1980 (Table 2 ) where three sowing dates had been practiced. The third sowing showed a marked decrease in yield. All three yield components were affected.

On the other hand when properly drilled in autumn, winter barley is generally well established in March, several weeks before spring types, and it shows ear emergences 15-20 days in advance, completing its maturity only 8-15 days before spring barley, if we consider conditions in Clermont-Ferrand for instance. Thus it typically matches the requirement for ideal timing of development according to environment, which is a reaction of good adaptation.

However winter barley varieties have to support the hazards of early autumn sowing such as BYDV, or the crop may be killed or damaged by frost, as was the case in 1979 in some parts of France and West Germany.

The yield potential of spring barley is not inferior - as far as such a comparison makes sense - and it has been found that, when water supply was sufficient, with cool temperatures in spring and few occasions where they surpassed $30{ }^{\circ} \mathrm{C}$ in June

Table 1. Increase of winter barley as a percentage of total barley acreage in NW European countries, 1965-1982.

\begin{tabular}{lllrrrrr}
\hline Year & \multicolumn{1}{l}{ Country } & \multicolumn{1}{l}{} \\
\cline { 2 - 8 } & B & D & DK & F & GB & IRL & NL \\
& & & & & & & \\
1965 & 17 & 28 & 0 & 11 & $4 ?$ & $0 ?$ & 11 \\
1970 & 16 & 31 & 0 & 11 & 5 & $0 ?$ & 8 \\
1975 & 26 & 39 & 0 & 20 & 7 & $0 ?$ & 6 \\
1980 & 85 & 59 & -0 & 53 & 31 & $0 ?$ & 23 \\
1982 & 84 & 48 & 1 & 55 & 42 & 7 & 16 \\
\hline
\end{tabular}

Source: EBC Report, 1982. 


\section{JESTIN}

Table 2. Delayed sowings of 3 varieties in 3 sites (1980). Resulting yield and yield components* (Berbigier \& Chery, 1981).**

\begin{tabular}{|c|c|c|c|c|c|c|c|c|c|c|c|c|c|}
\hline \multirow[t]{2}{*}{ Site } & \multirow{2}{*}{$\begin{array}{l}\text { Sowing } \\
\text { date }\end{array}$} & \multicolumn{3}{|c|}{ cv. Europa } & \multicolumn{5}{|c|}{ cv. Jupiter } & \multicolumn{4}{|c|}{ cv. Cytris } \\
\hline & & $\mathrm{E} / \mathrm{m}^{2}$ & $\mathrm{~K} / \mathrm{E}$ & TKW & $\mathrm{Y}$ & $\mathrm{E} / \mathrm{m}^{2}$ & $\mathrm{~K} / \mathrm{E}$ & TKW & $Y$ & $\mathrm{E} / \mathrm{m}^{2}$ & $\mathrm{~K} / \mathrm{E}$ & TKW & $\mathrm{Y}$ \\
\hline \multirow{3}{*}{$\begin{array}{l}\text { Mont- } \\
\text { pellier }\end{array}$} & $19 / 11$ & 100 & 100 & 100 & 100 & 94 & 104 & 98 & 104 & 75 & 124 & 113 & 110 \\
\hline & $08 / 01$ & 93 & 90 & 113 & 96 & 90 & 75 & 99 & 88 & 74 & 89 & 113 & 97 \\
\hline & $18 / 02$ & 80 & 92 & 100 & 82 & 71 & 89 & 93 & 74 & 72 & 92 & 95 & 69 \\
\hline \multirow{3}{*}{$\begin{array}{l}\text { Clermont- } \\
\text { Ferrand }\end{array}$} & $29 / 0$ & & 100 & 10 & 100 & 10 & 107 & 89 & 100 & 76 & 110 & 105 & 96 \\
\hline & $13 / 03$ & 94 & 105 & 108 & 95 & 101 & 100 & 98 & 100 & 72 & 105 & 114 & 94 \\
\hline & $31 / 04$ & 69 & 111 & 106 & 80 & 72 & 103 & 101 & 82 & 63 & 113 & 114 & 79 \\
\hline \multirow[t]{3}{*}{ Dijon } & $04 / 0$ & 10 & 100 & 10 & 100 & 98 & 113 & 100 & 102 & 75 & 113 & 10 & 84 \\
\hline & $24 / 03$ & 101 & 98 & 100 & 96 & 101 & 102 & 88 & 100 & 80 & 111 & 104 & 87 \\
\hline & $08 / 04$ & 91 & 100 & 95 & 81 & 93 & 203 & 90 & 88 & 84 & 106 & 102 & 90 \\
\hline
\end{tabular}

* As a percentage of Europa, 1st sowing in each site.

${ }^{* *} \mathrm{E}=$ ear $\mathrm{K}=$ kernels; TKW $=$ thousand-kernel weight; $\mathrm{Y}=$ yield.

or July, as was the case in 1980 in Clermont-Ferrand, modern spring barley varieties can yield 8 tonnes/ha, and equal or overcome winter barley varieties. However when considering the average yield of spring barley over many years it appears much more irregular than that of winter barley.

One might be surprised to see that this better overall adaptation of winter types has not been exploited earlier. It seems reasonable to assume that the progress provided by varieties such as Kenia, Rika and Proctor, particularly concerning yield and lodging resistance, together with modern cultivation practices - relatively high fertilizer applications - has favoured the expansion of spring barley. However from 1965 onwards new winter varieties have been released which were suitable for modern cultivation systems. In this respect, the variety Ager, a winter six-row type has been the breakpoint for this development in France for instance, as were later Alpha, Sonja and Igri for the two-row types, and many other since that time. The critical feature for both two-row and six-row types was improved lodging resistance. In addition, two-row types had high tillering potential, together with other good yield components.

The last general question to be raised about winter barley adaptation concerns the choice between six-row and two-row types. Here again there is little experimental evidence. There are situations where exclusively 6-row barley is cultivated, in particular when adaptation conditions require a short growing period and perhaps a shorter tillering stage to spare water and to escape drought (in northern Africa, Australia, Middle East, etc.), or to escape cold and moist season (Norway, Finland, etc.). The higher number of grains per ear in six-row types gives there sufficient grains $/ \mathrm{m}^{2}$, whereas two-row types rely heavily on the tillering period to reach this number; thousand-kernel weight and ear fertility cannot always compensate for insufficient tillering, at least among spring barleys. This critical aspect of tillering may 


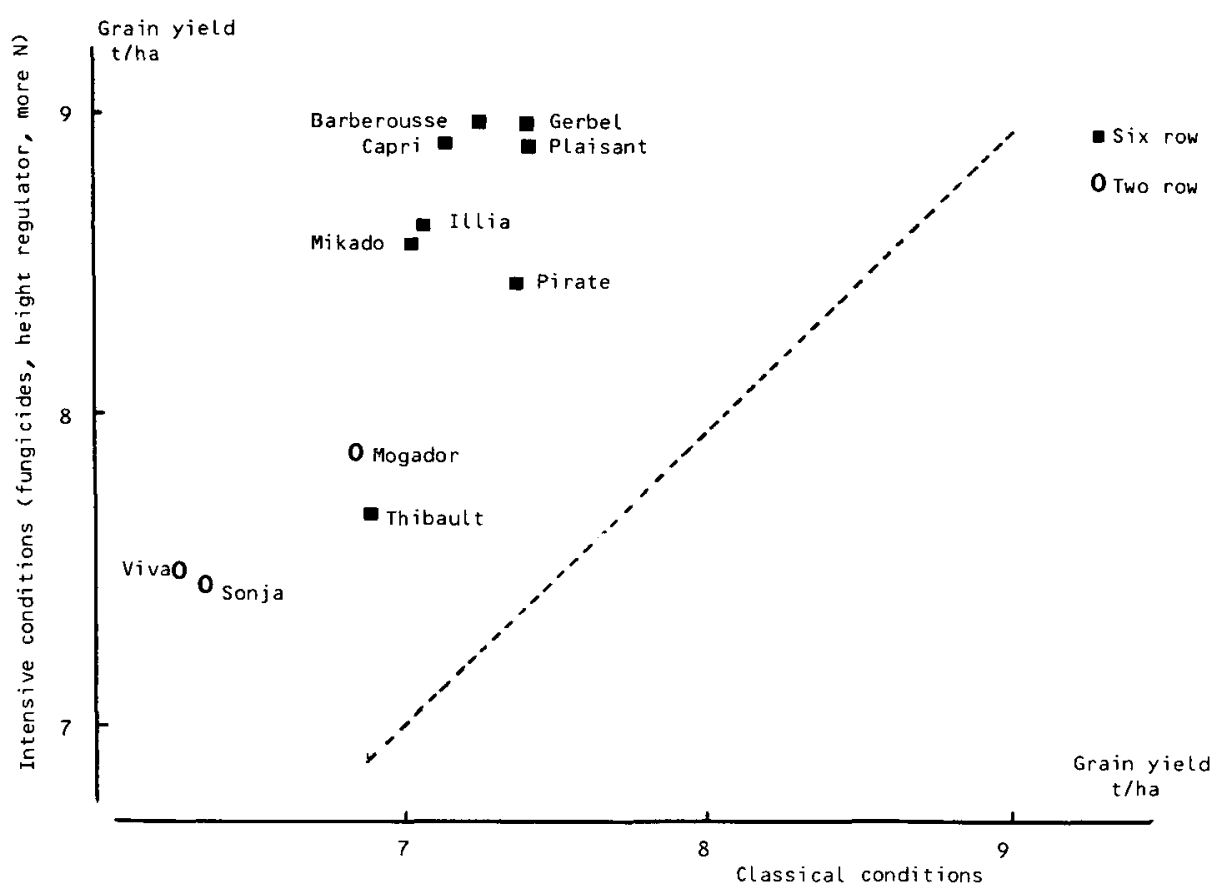

Fig. 1. Comparison of two-row and six-row winter barley in classical and intensive conditions at Saulzet (France). Three-year average (1981-1982-1983). ITCF data.

explain sometimes also why two-row winter barley is often inferior in yield compared to six-row types. The result of a field trial near Clermont-Ferrand examplifies this statement (Fig. 1). In France, during the 3 years 1981 to 1983, the best six-row varieties yielded 5 to $10 \%$ better in average than the best two-row ones, and this in most regions (Codron et al., 1984) (see Table 3).

Of course, it is not excluded that in the future new two-row varieties will come

Table 3. Comparison of two-row and six-row varieties of winter barley in several French zones 3 years 1981-83.*

\begin{tabular}{lrrrrr} 
& East & $\begin{array}{l}\text { Paris } \\
\text { region }\end{array}$ & $\begin{array}{l}\text { Central } \\
\text { plaines }\end{array}$ & West & Southwest** $^{* *}$ \\
Mean of 2 best two row & 95.5 & 98.5 & 95.5 & 93.8 & 96.6 \\
Mean of 2 best six row & 103.8 & 106.5 & 103.3 & 104.2 & 105.9 \\
Difference (\%) & 8.3 & 8.0 & 8.0 & 10.4 & 9.0 \\
\hline
\end{tabular}

* Differences are weaker with some more rec nt two row types (data: Institut Technique des Céréales et Fourrages, 1984).

** 4 years $1980-1983$. 
closer to the best six-row winter barley, as it was almost the case already for Flamenco in 1982 EBC trials.

There have been few studies of winter barley adaptation in NW Europe in comparison with those on spring barley. However Dr Feekes had initiated a study on winter barley development in comparison with spring barley (not published).

Some results or approaches utilized for winter wheat may serve for barley, if they are not directly transposable. In particular the pattern of reaction to day-length and vernalizing temperatures may be more or less similar. However the two species are not strictly comparable: tillering is more important in barley, and some adverse correlations between stiffness of straw, thinness of husks and resistance to grain shedding may complicate the adaptation problem.

Recently a greater emphasis was put on making studies with winter barley (Kirby \& Appleyard, 1980; Lupton, 1982; Russell et al., 1982). The latter work shows that even with appreciable winter damage, the best winter types could outclass the spring types. Even without frost damage, the pattern of fertile tiller production is not simple. In an experiment of Garcia del Moral et al. (1984), the two-row varieties had a lower initial tillering than the 6-row types studied, but after tiller loss in the course of development, two-row genotypes had more ears per plant. This may be only chance, as there were only 6 genotypes in the trial.

Finally, there is now a tendency to very early sowing of winter barley in September - which might be reversed, where BYDV is a major risk despite possible insecticide use. Adaptation studies should certainly take into account this trend.

\section{Recent European cooperative work on spring barley adaptation}

\section{Multi-site spring barley experiments}

Around 1975, despite the outstanding genetical progress in European countries which had led to improved varieties such as Kenia, Rika, Piroline, Proctor, Julia and Aramir, spring barley yields appeared too irregular over several years. Moreover at that time semi-dwarf advanced lines had been selected and their adaptation to various growing conditions were not well known.

This background encouraged breeders to compare their selections in a much wider range of environments than usual. As a first step, Mr Jenkins (P.B.I., Cambridge, U.K.) organized with Mr Froidmont (Gembloux, Belgium) and Mr Berbigier (Clermont-Ferrand, France) in 1976 - a year still famous for its exceptional drought - a series of spring barley trials on 7 sites. The following year, on the late Dr Feekes' initiative, and thanks to the numerous and solid friendly acquaintances he had in the circle of European cereal breeders, these trial series were extended (also in 1978) to 22 sites located in 12 countries. At the same time, the number of varieties studied in this European Spring Barley Adaptability Nursery (ESBAN) was raised from 25 to about 50 , with a broadened genetic basis; for example, Finnish six-row varieties, Swedish and Hungarian accessions were included (see Fig. 2 and Table 4).

In a circular letter, the late Dr Feekes wrote in February 1976: 'Breeders as well as institutes, however, have not consciously done much about another highly desir- 


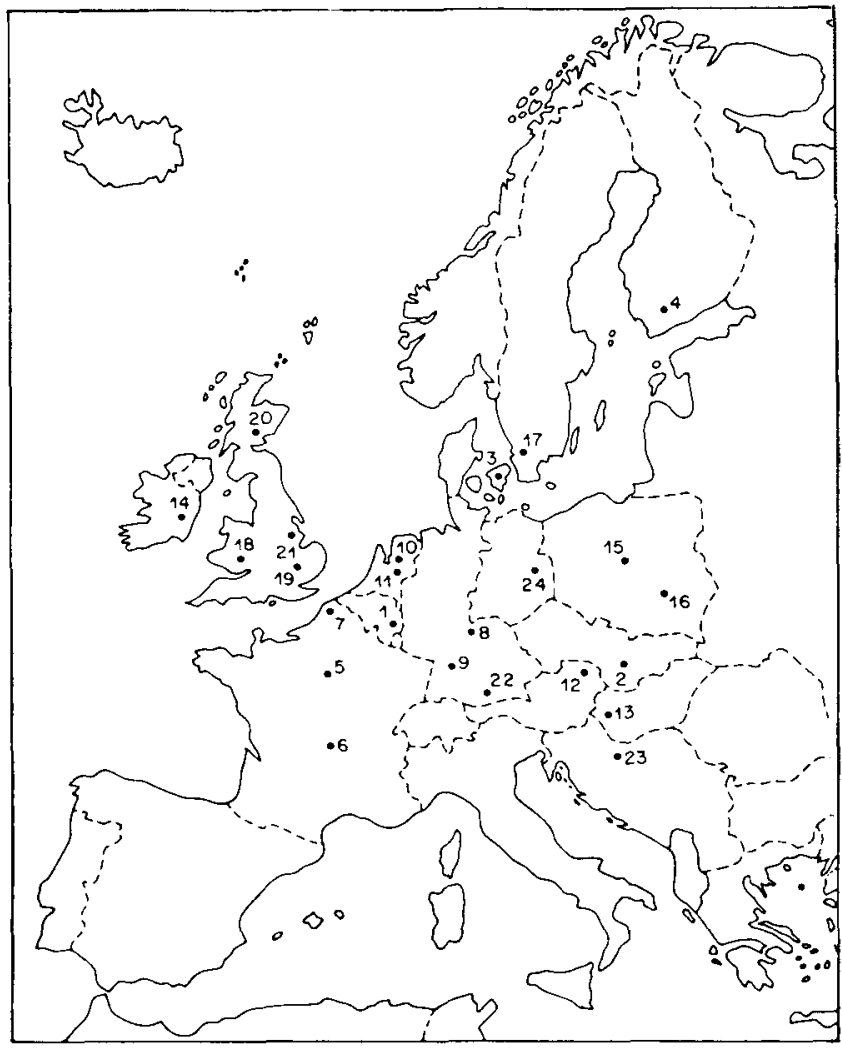

$800 \mathrm{Km}$

Fig. 2. ESBAN network (24 sites in 1978).

Table 4. Varieties or lines initially proposed for ESBAN 1977, seed multiplication organized by Nederlands graan centrum.

\begin{tabular}{llll}
\hline 1. Karri & 14. Trumpf & 26. Multum & 39. Mazurka \\
2. Otra & 15. Union & 27. MK 42 & 40. Pirouette \\
3. Lise & 16. Carina & 28. MV 46 & 41. Ho 65 \\
4. Varde & 17. Kiebitz & 29. MK 421 & 42. Athos \\
5. Moyar & 18. H 109 & 30. Georgie & 43. Berenice \\
6. Gunilla & 19. H 150 & 31. Ark Royal & 44. Betina \\
7. Ingrid & 20. H 172 & 32. RPB 471/72 & 45. Ceres \\
8. Tellus & 21. Nudinka & 33. Maris Mink & 46. CF 20 \\
9. Mona & 22. Hora & 34. HB $878 / 631$ & 47. CF 25 \\
10. SV 72190 & 23. Indira & 35. HB $889 / 40$ & 48. CF 113 \\
11. SV 68241 & 24. Adorra & 36. Aramir & 49. Velebit \\
12. Zita & 25. Uta & 37. Cebeco 7311 & 50. Armelle \\
13. KM 1192 & & 38. Julia &
\end{tabular}




\section{JESTIN}

able characteristic: adaptability. Nevertheless yield stability and adaptability are essential for the spread of a variety. At the same time the complex nature of these characteristics makes them difficult to investigate and use, in breeding work as well as in supporting research.'

Later on, other series have been or are being carried out (Joint European Spring Barley Trials) on a narrower scale, both for sites and for entry numbers (Ellis \& Schmuetz, 1981; Riggs, 1984).

\section{Purpose of ESBAN or similar designs}

Unlike EBC trials, where the primary design is to test potential suitability of new barley varieties for the malting and brewing industries, the ESBAN series served both to assess the actual adaptation of new varieties to soil-climate environments and to determine whenever possible the reasons accounting for wide adaptation of genotypes. Such trials could also provide a wide material basis to view the adaptation problems, and perhaps to define practical methods to deal with this question in breeding programmes (e.g. which characters are most important for good adaptation).

The trials were treated with fungicides, as the aim of the studies concerned mainly variety $\times$ soil-climate interactions.

\section{Main results of multisite trials}

1. A first interesting result - at least for the participants - has been a better knowledge of their barley material.

2 . The 1976 series showed a highly significant genotype $\times$ site interaction, the corresponding variance components, notably for yield, equalling or overcoming the genotypic component, thereby making meaningless or quite relative the general sense of this main effect. In comparison, the site effect was extremely large. The interactions did not fit with the Finlay-Wilkinson (1963) linear model. However the range of variation between genotypes was rather narrow, as the varieties for these trials were chosen for their high yielding capacity. The site average range was about twice as large as the genotype variation (see Table 5).

There were differences between varieties for yield stability (Table 6). Site groups (Cambridge-Gistel; Bastogne-Clermont-Mons) with correlated valietal response

Table 5. Spring barley cooperative trials, 1976; 25 genotypes $\times 7$ environments. Variance analysis for yield over sites (Riggs, 1979), testing of the Finlay \& Wilkinson linear model.

\begin{tabular}{lccc}
\hline Source of variation & D.F. & Mean square & Signif. \\
Sites & 6 & 6924 & $* * *$ \\
Genotypes & 24 & 147 & $* * *$ \\
Sites $\times$ genotypes interaction & 144 & 45 & $* * *$ \\
- heterogeneity between regression & 24 & 34 & N.S.1 \\
- pooled deviations & 120 & 48 & $* * *$ \\
(Repetitions within sites) & 21 & 42 & 11 \\
Residual error & 504 & & \\
\hline
\end{tabular}

\footnotetext{
1 Against fooled deviations.
} 
Table 6. Spring barley cooperative trial 1976; 25 genotypes in 7 environments (from Riggs, 1979).

\begin{tabular}{lllr}
\hline Variety & Source & $\begin{array}{l}\text { Mean yield t/ha } \\
\text { (7locations) }\end{array}$ & $\begin{array}{r}\text { Genotype } \times \text { environment* } \\
\text { variance component }\end{array}$ \\
1. Ashdon (HB 869-8) & PBI-GB & 4.7 & 106 \\
2. Jupiter (878-631) & PBI-GB & 5.0 & 99 \\
3. Astina (HB 878-1330) & PBI-GB & 4.8 & 78 \\
4. Minak (889-18) & PBI-GB & 4.9 & 90 \\
5. Yamina (889-40) & PBI-GB & 4.8 & 119 \\
6. Georgie & RPB-GB & 5.3 & 70 \\
7. CF 25 & INRA CF-F & 5.0 & 64 \\
8. CF 27 & INRA CF-F & 5.3 & 75 \\
9. CF 42 & INRA-CF-F & 5.0 & 86 \\
10. CF 113 (naked) & INRA CF-F & 4.5 & 43 \\
11. CF 132 & INRA CF-F & 4.8 & 62 \\
12. Berenice & INRA CF-F & 4.6 & 61 \\
13. HO 423-3 & Gembloux-B & 5.2 & 49 \\
14. HO 426-6 & Gembloux-B & 5.0 & 75 \\
15. HO 465-1 & Gembloux-B & 5.2 & 78 \\
16. Hebe & Heverle-B & 4.9 & 54 \\
17. Golden promise & Milnes-GB & 4.7 & 85 \\
18. Midas & Milnes-GB & 4.7 & 105 \\
19. Ark Royal & RPB-GB & 4.7 & 119 \\
20. Maris Dingo & PBI-GB & 4.4 & 82 \\
21. 5359 B & Secobra-F & 4.8 & 86 \\
22. 5577 C & Secobra-F & 7.6 & 108 \\
23. Aramir & Cebeco-NL & 5.0 & 58 \\
24. Maris Mink & PBI-GB & 4.7 & 74 \\
25. Julia & Cebeco-NL & 4.9 & 79 \\
\hline
\end{tabular}

* Contribution to the total interaction variance.

could be distinguished. A multivariate analysis over 3 sites led to the separation of British varieties from most of continental ones. These statistical analyses were carried out at the P.B.I., Cambridge (Riggs, 1979) and other at INRA-Versailles (Denis, 1979).

3. For the 1977 and 1978 series, a statistical procedure of ascending hierarchical classification was used to define variety groupings, according to similar genotypic responses. Symmetrically a site grouping was performed. With this method, no preconceived structure of the interaction data is supposed (Denis, 1979). No soil or climate data had been recorded, but an indication of the relevance of these site groupings could be obtained, taking several long-term climate data found in the Agroclimatic Atlas of Europe (Thran \& Broekhuizen, 1965). Some within-group associations - Clermont with Svalöf for example - could not be explained by climate and may have come from soil fertility or cultivation practices. The groups comprised sometimes quite different genotypes, such as CF 25 (= Cytris), an early type with large kernels and Trumpf, which is late with short straw. Some groups were made of a single variety having a comparatively original response to environment; for instance, the early Finnish six-row spring barley Otra, and some others, had a good 
yield and adaptation at Nikkila (SF) only, a site where a short growth cycle is required. Nikkila, perhaps due to local photoperiodic and temperature conditions, forms a site-group alone, very different from the other groups. Apart from early spring 6-row types, the only relatively well adapted there were late two-row types such as Ark Royal.

The variety $\times$ year interactions were not important, except for some varieties, as the climate in 1977 and 1978 has been relatively close to the average, and as a result the grouping of the two years were almost similar. The interactive effects could not be explained in term of physiological response, as environmental data were lacking. The authors noticed (Berbigier \& Denis, 1981) that among high-yielding varieties, relatively diversified genotypes were found, as regard origin, earliness, plant height, thousand-kernel weight, etc. This demonstrated, in addition, the possibility of breeding for large areas in Europe, but excluding environments such as Nikkila. Site grouping in 1978 distinguished a large 'maritime' group in contrast with the sites of Central Europe, which had each their specific ranking for varietal adaptation.

4. A more complete account as regards varietal performances as well as details on interactions has been given by Jenkins (1976) and Riggs (1979) for 1976 series, and by Berbigier, Denis \& Dervin (1980) and Berbigier \& Denis (1981) for 1977 and 1978 ESBAN series.

\section{Other related research}

In parallel with these ESBAN series, some special research had been programmed on particular factors of adaptation. For example, Kirby \& Appleyard (1980) have carried out in Cambridge (P.B.I.) a special investigation on the effect of photoperiod on development. They used partially controlled glasshouse conditions, on a subset of 10 varieties included in the ESBAN. Differences were found for photoperiod response, but from the bulk of the data no clear relation with grain yield could be detected. But similarly to what had been observed in ESBAN field trials, the early six-row types such as the Norvegian barley Lise reflected a typical interactive contrast with the other genotypes at conditions of long days $(20 \mathrm{~h})$.

In a different way, while using multilocation successional sowings, Berbigier \& Chery (1981) have compared the adaptation of CF 25 (= Cytris), Jupiter (HB $878 / 631)$ and Europa ( $=$ H 150) (Table 2). In the 3 sowings at each site, Cytris had a considerably lower number of ears $/ \mathrm{m}^{2}$, but could compensate remarkably for this by a higher number of grains/ears and a larger kernel weight, as seen from Table 2 . This allows that variety to reach almost the yield of later genotypes such as Jupiter or Europa when conditions are acceptable for the late varieties (Clermont-Ferrand, 1st sowing 29/2). In water deficit conditions, the earliness of Cytris usually gives it an advantage over later varieties. In cool moist conditions favouring late genotypes, however, it may often be surpassed.

\section{Possible methods to analyse adaptation and $G \times$ E interactions}

Sometimes, especially for current breeding application, a quite practical procedure is used: tables with site yields of each variety as percentage of controls or of general 
mean are made. These data give a quick impression about the stability of the varieties. A further step may consist in trying to relate them to other field observations.

When carrying out analyses with different models for adaptation or interaction some points seem too frequently disregarded, such as the fact that in such a twoway table an interaction effect is wholly relative, being conditional to the whole array of sites and varieties (Fripp \& Caten, 1973). Yet one tends to calculate varietal stability parameters: these might be completely different if other varieties and sites were considered. Often the sites are used partly because they are available, and the genotypes also because they exist and are likely enough to be adapted except for the inclusion of well known controls. Moreover the range of genetic variation appears sometimes (Gotoh \& Chang, 1979) implicitly restricted to start with, because it seems pointless to include probably unadapted genotypes. Often, with current error variation coefficient of 3 to $8 \%$ or more in trials, the interaction effects which can be estimated, however significant, are not so much greater than the error variance and this may lead to some suspicion about the reality of the conclusions one might attempt to draw.

Often trial series for adaptation are carried out over two or three years: as there is frequently an important annual climatic particularity effect on almost all sites of the area considered, the site $\times$ year set of environments as a whole is not really wellbalanced, site variation being superfluously represented and year climatic sampling being insufficient. In France, in the case of maize, the years 1965-75, except 1973, were more or less favourable for the crop, whereas in the period 1976-84 there were regularly some adverse conditions, except in 1982! (M. Pollacsek, personal communication, 1984).

For the aim of grouping varieties and sites, many models and algorithms have been proposed (Freeman, 1973; Denis, 1979) to deal with the interaction matrix, for example graphical structuring or automatic classification. In the latter case, different algorithms are applicable to grouping of varieties or sites. Denis (1979), Berbigier \& Denis (1981) used the ascending hierarchical classification. A distance measure between two individuals is defined, for example, as the sum of squares of deviations of interaction between these individuals. After that, a classification algorithm permits one to build a dendogram, and a level of truncation is then chosen in this dendogram to define some groups, also called clusters (Williams, 1971). This method has been widely used (Abou-el-Fitouh et al., 1969; Mungomery, Shorter \& Byth, 1974; Byth, Eisemann \& De Lacy, 1976).

The groups may then serve to select the most discriminant breeding sites, and conversely the most contrasted genotypic reactions, which is a useful information when planning further experiments.

There are also numerous models to try to adjust the interaction matrix to a statistical law. The joint regression model (Yates \& Cochran, 1938; Finlay \& Wilkinson, 1963), when it works - and this is far from being always the case - is very popular, because the interaction effects are explained by a simple function of main effects, and the graphic representation is easy, clear and striking. One may also hope to find rather easily the biological phenomenon underlying such a straightforward form. Assuming the variety $(i)$ and site $(j)$ array of yield data $y_{i j k}$, with $k$ within-site repe- 


\section{JESTIN}

titions, with the general mean $M$, the main effects $\mathrm{G}_{i}$ (variety) and $E_{j}$ (site) of the variance analysis, one considers the model:

$$
Y_{i j k}=M+G_{i}+E_{j}+R_{i j}+e_{i j k}
$$

with the residual error term $e_{i j k}$. The interaction effect is $R_{i j}$.

In the model each genotype will be characterized besides its main effect by a regression coefficient $b_{i}$. The yield of each genotype is regressed in all sites on a site value which is precisely provided for each site by the mean performance of all the varieties of the array in that site.

Thus, $Y_{i j k}=M+G_{i}+E_{j}+b_{i} \cdot E_{j}+D_{i j}+e_{i j k}$ where $D_{i j}$ is the deviation from the regression; it is the part of $R_{i j}$ not explained by the regression.

This model is very well adapted when one single external factor causes the interaction reactions, as water supply in the famous Finlay $\&$ Wilkinson example. But it often fails to be applicable, as many factors completely uncorrelated have independantly created a large part of the interactions. In such a case there is no reason to find many effects of different origin on the same straight line. Sometimes also the range of genetic and/or site variations are so artificially restricted in the variety $x$ site array that the linear pattern of interaction due to a given factor no longer appears.

A more general multiplicative form of interaction adjustment consists in a principal component analysis on the interaction matrix (Mandel, 1971). Here a few principal components (one or two generally) serve to break down the interaction $R_{i j}$ :

$R_{i j}=\theta_{1} \mu_{i 1} v_{j I}+\theta_{2} \mu_{i 2} v_{j 2}+e^{\prime}{ }_{i j k}$.

There are approximative tests (Johnson \& Graybill, 1972) to test the significance of successive principal components.

This method has been also widely used (Jestin, 1974; Bernard \& Guedes-Pinto, 1983; Brian, 1978).

Finally, a last group of methods consists in taking into account external information: physical records of the environment or biological measurements on the varieties are used as covariates to calculate regression with interaction effects. This makes possible in some cases the agronomical or physiological explanation of the interaction effects observed. Such methods have been described by Freeman \& Perkins (1971), Fripp (1972), Hardwick \& Wood (1972), Wood (1976), Freeman \& Crisp (1979), Denis (1980) and Denis \& Vincourt (1982). Some examples of such applications are found in the literature (Saeed \& Francis, 1983; Denis et al., 1980).

\section{Breeding methods for adaptation}

\section{Current practices}

When breeding for wide adaptation, it is necessary to assess sufficiently early the genotype stability over many environments. In the very early stages of the selection, this is not feasible, and one must select according to predetermined criteria for some characters: not too early or late, sufficiently short, a fertile ear, with large kernels, an acceptable level of tolerance to major diseases. It is not a problem in the first steps of the selection cycle, because screening for these minimum requirements in F2, for example (or even F3) is safe enough. In the F3 rows or small plots, there is 
still a need to select for characters with medium to high heritability, such as lodging resistance and tillering potential.

At the following stage (F4) there are often microplot trials in one site - sometimes without replication - and disease or adaptation nurseries for special characters such as frost damage, drought, humid conditions in other sites which permit discarding of progenies having serious critical defects. Even at this early stage some breeders sow small trials with each replication in a remote and different environment.

This makes possible a first selection for yield stability over environments. It has sometimes been proposed to grow F3 or equivalent generations in duplicate. This may be efficient but makes heavier the screening work. For self-pollinated species, such as barley, where there are usually many thousands of F3 progenies, and even taking into account the facilities provided by computers, adequate managing a F3 in a single site is already quite a task. On the other hand, for spring barley, there is a possibility of alternate generations in the Southern Hemisphere, in New Zealand for example, which is in fact widely used by breeders from different regions. Multiple successional sowings are also costly in time and place, and are frequently practices on potential parents of crosses or more advanced F5-F7 selections only. Multisite trials beginning in F4 or F5 may give sufficient empirical information about developmental adaptation. They seem also to be widely carried out among breeders, with sometimes several hundreds of selections in three or four sites.

\section{Examples of breeding specifically for adaptation}

Experimental simultaneous selection of two-row winter barley in two sites (U.K. and Italy) has been reported by Sage, Roffey \& Stanca (1984) over four years, from F3 to F5. There was no original kind of material selected in each of both sites which would then show no adaptability to the other site. Material with best site-specific adaptation had only a small local yield advantage over lines having wide adaptation to both sites, and apparently selection for specific adaptation was not effective. It appeared that material discarded one year in one site could, after reselection on the basis of response in the other site, prove acceptable in the first site. Only yield trials in F5 were able to assess some degree of adaptation safely.

A similar experiment had been carried out earlier in Canada (St-Pierre, Klinck \& Gauthier, 1967) with 6-row spring barley progenies from F2 to F8 in 2 sites in parallel. Here yields of the progenies were estimated from F2 onwards. Material selected in each site was exchanged every year. Adaptation of the resulting lines in F7 or F8 was tested in both sites in field trials. Material selected in one of two sites proved to have better wide adaptation. But the strains selected in alternate locations in successive years had the best adaptation on the whole.

Possible use of the adaptability studies to improve the corresponding breeding procedure

Some aspects of the breeding procedures may certainly be improved by using the results obtained from trial series such as ESBAN, or ecophysiological studies.

- The analyses may help to define the sites which are more appropriate to screen

Neth. J. agric. Sci. 33 (1985) 


\section{JESTIN}

breeding material in early generations for a particular adaptation zone.

- Experimental designs and sometimes computer programmes or statistical methods are likely also to be transferred. This has been done with silage maize by Vincourt \& Gallais (1983), for example, by using a genotype-on-phenotype regression method.

However the main result remains the basic knowledge obtained for the benefit of the breeder. Indeed, the requirements for current breeding activity must be quite pragmatic and flexible, a very large amount of material must be treated at a low cost per unit. This contrasts obviously with the high number of parameters recorded on soil, climate and growing plants in the course of an ecophysiological experiment lasting several years on many sites. But even this methodology could be of some use regarding the more advanced material in a breeding programme — and is actually applied by some breeders.

\section{Conclusion}

The question of adaptation or adaptibility concerning barley is very important. The aspects concerning adaptation to diseases and pests should perhaps have been integrated, as the breeder cannot separate them from soil-climate problems. Other aspects concern selection for limit environments, where adaptation to one mere factor in its extreme expression is critical. This is the case of drought, frost, acidity, or salinity etc. in different areas. The basic scheme then is to screen for an acceptable reaction to a controlled level of the factor considered sometimes in artificial conditions and to look for possible transgressions. In such situations it is possible that mutation breeding, recurrent selection methods etc. prove to be useful.

Multi-location field experiments in very different environments may be useful, perhaps still more when the total area explored is larger than the zone which is considered as the adaptation objective. Even sophisticated statistical procedures are likely not to replace the aid brought by the classical ecophysiological approach, which is an unequalled method to obtain a better understanding of plant-environment relations.

\section{Acknowledgement}

I am indebted to Drs G. Jenkins, F. Vear and N. M. de Vos for kindly re-reading the English manuscript.

\section{References}

Abou el Fitouh, H. A., J. O. Rawlings \& P. A. Miller, 1969. Classification of environments to control genotype by environment interactions with an application to cotton. Crop Science 9: 135-140.

Aspinall, D., 1966. Effects of daylength and light intensity on growth of barley. IV. Genetically controlled variation in response to photoperiod. Australian Journal of Biological Science 19: 517-534.

Aspinall, D. \& L. G. Paleg, 1964. Effects of daylength and hight intensity on growth of barley. III. Vegetative development. Australian Journal of Biological Science 17: 807-822. 
Baker, R. J., 1969. Genotype $\times$ environment interactions in plant breeding. Canadian Journal of Plant Science, 40: 743-751.

Becker, H. C., 1981. Correlations among some statistical measures of phenotypic stability. Euphytica 30: $835-840$.

Berbigier, A. \& J. Chery, 1981. Incidence du milieu sur l'élaboration du rendement chez l'orge de printemps. Interaction avec le génotype. Compte rendu Contrast DGRST M 8.70637-ENSA, Montpellier, France, $27 \mathrm{pp}$.

Berbigier, A. \& J. B. Denis, 1981. Interaction variété-lieu. Analyse du rendement d'orges de printemps en 1978. Comparaison de 1977 et 1978. Agronomie 1(8): 641-650.

Berbigier, A., J. B. Denis \& C. Dervin, 1980. Interaction variété-lieu: analyse du rendement d'orges de printemps. Annales de l'Amélioration des Plantes 30(1): 79-94.

Bernard, M. \& H. Guedes-Pinto, 1983. Etude comparative de quelques cultivars de blé, seigle et triticale dans le nord du Portugal. II. Adaptation du matériel végétal au milieu. Agronomie 3(8): 723-733.

Brian, C., 1978. L'interprétation statistique des essais 'deux-voies': décomposition factorielle des résidus et l'étude de la structure des interactions. Annales de l'Amélioration des Plantes 28(4): 395-410.

Byth, D. E., R. L. Eisemann \& L. H. De Lacy, 1976. Two-pattern analysis of a large data set to evaluate genotypic adaptation. Heredity 37(2): 215-230.

Chowdury, R. K., V. P. Singh \& R. K. Singh, 1982. Efficiency of various stability models for ranking barley genotypes. Cereal Research Communication 10(1-2): 95-101.

Codron et al., 1984. Variétés de céréales d'hiver, essais 1983. Perspectives agricoles (juin 1984) No 82: 15-36.

Cooper, J. P., 1960. Short day and low-temperature induction in Lolium. Annals of Botany 24: 232-246.

Denis, J. B., 1979. Structuration de l'interaction. Biométrie Praximétrie 19: 15-34.

Denis, J. B., 1980. Analyse de régression factorielle. Biométrie Praximétrie 20: 1-34.

Denis, J. B., J. P. Gouet, J. Tranchefort, 1980. Méthodes d'étude de la structuration de l'interaction génotype $\times$ milieu application à l'analyse d'essais de blé tendre. Biométrie et Génétique (1980): 98109.

Denis, J. B., P. Vincourt, 1982. Panorama des méthodes statistiques d'analyse des interactions génotype $\times$ milieu. Agronomie 2(3): 219-230.

Donald, C. M., 1968. The breeding of crop ideotypes. Euphytica 17: 385-403.

Eberhart, S. A. \& W. A. Russel, 1966. Stability parameters for comparing varieties. Crop Science 6: 3640.

Ellis, R. P. \& W. Schmütz, 1981. Collaborative spring barley trials in Europe. In: Barley Genetics IV, p. 163-166. Edited by the Subcommittee of the IVth International Barley Genetics Symposium. University Press, Edinburgh, 974 pp.

Evans, L. T., 1975. The physiological basis of crop yield. In: L. T. Evans (Ed.), Crop physiology: some case history, p. 327-355. Cambridge University Press, Cambridge, 374 pp.

Evans, L. T. \& I. F. Wardlaw, 1976. Aspects of the comparative physiology of grain yield in cereals. Advances in Agronomy 28: 301-359.

Evans, L. T., I. F. Wardlaw \& R. A. Fischer, 1975. Wheat. In: L. T. Evans (Ed.), Crop physiology: some case history, p. 101-149. Cambridge University Press, Cambridge, 374 pp.

Feekes, W., 1941. XII. De tarwe en haar milieu. Verslagen van de Technische Commissie, Groningen, Netherlands, p. 519-886.

Finlay, K. W., 1971. Breeding for yield in barley. In: R. A. Nilan (Ed.), Barley genetics. II. Proceedings of the 2nd Barley Genetics Symposium, p. 338-345. W. S. University Press, Pullman, Wash., USA, $622 \mathrm{pp}$.

Finlay, K. W. \& G. N. Wilkinson, 1963. The analysis of adaptation in a plant breeding programme. Australian Journal of Agricultural Research 14: 742-754.

Flood, R. G. \& G. M. Halloran, 1984. The association of vernalization and photoperiod responses in wheat. Cereal Research Communications 12(1-2): 5-11.

Freeman, G. H., 1973. Statistical methods for the analysis of genotype $\times$ environment interactions. $\mathrm{He}$ redity 31(3): 339-354.

Freeman, G. H. \& P. Crisp, 1979. The use of related variables in explaining genotype-environment interactions. Heredity 42(1): 1-11. 


\section{JESTIN}

Freeman, G. H. \& J. M. Perkins, 1971. Environmental and genotype-environmental component of variability. VIII. Relations between genotypes grown in different environments and measures of these environments. Heredity 27: 15-23.

Fripp, Y. J., 1972. Genotype $\times$ environment interactions in Schizophyllum commune. II. Assessing the environment. Heredity 28: 223-238.

Fripp, Y. J. \& C. E. Caten, 1973. Genotype $\times$ environment interactions in Schizophyllum commune. III. The relationship between mean expression and sensitivity to change in environment. Heredity 30 : 341-349.

Gallagher, J. N., P. V. Biscoe \& R. Dennis-Jones, 1983. Environmental influences on the development, growth and yield of barley. In G. M. Wright \& R. B. Wynn-Williams (Eds.), Barley: production and marketing, p. 21-49. Special Publication No 2. Agronomy Society of New Zealand, Christchurch, N.Z., 163 pp.

Garcia del Moral, L. F., J. M. Ramos \& L. Recalde, 1984. Tillering dynamics of winter barley as influenced by cultivar and nitrogen fertilizer: a field study. Crop Science 24: 179-181.

Gotoh, K. \& T. T. Chang, 1979. Crop adaptation. In: J. Sneep \& A. J. T. Hendriksen (Eds.), Plant breeding perspectives, p. 234-261. Pudoc, Wageningen, Netherlands, 435 pp.

Gustafson, A., G. Ekman \& I. Dormling, 1974. Phytotron ecology of mutant genes. IV. Variability photoperiod and phenotypic traits. Hereditas 76: 137-144.

Hardwick, R. C. \& J. T. Wood, 1972. Regression methods for studying genotype $\times$ environment interaction and no replication. Heredity 28: 209-222.

Jenkins, G. et al., 1976. Genotype $\times$ environment studies. Annual Report of the Plant Breeding Institute, Cambridge, $50 \mathrm{pp}$.

Jestin, L., 1974. Les variations de la teneur en proteines brutes chez l'orge selon la variété et le milieu: étude préliminaire à partir d'essais culturaux. Annales de l'Amélioration des Plantes 24(4): 377-388.

Johnson, D. E. \& F. A. Graybill, 1972. An analysis of a two-way model with interaction and no replication. Journal of the American Statistician Association 67: 388-394.

Kirby, E. J. M., 1969. The effect of sowing date and plant density on barley. Annals of Applied Biology 63: 513-521.

Kirby, E. J. M. \& M. Appleyard, 1980. Effects of photoperiod on the relation between development and yield per plant of a range of spring barley varieties. Zeitschrift für Pflanzenzüchtung 85: 226-239.

Kirby, E. J. M. \& M. Appleyard, 1980. Morphogenesis. In: Annual report P.B.I., p. 99-100. P.B.I., Cambridge, $136 \mathrm{pp}$

Lupton, F. G. H., 1982. Recent advances in cereal breeding. Netherlands Journal of Agricultural Science 30: $11-23$.

Mandel, J., 1971. A new analysis of variance model for non-additive data. Technometrics 13(1): 1-18.

Mandel, J., 1972. Principal components, analysis of variance and data structure. Statistica Neerlandica 26: $119-129$.

Mungomery, V. E., R. Shorter \& D. E. Byth, 1974. Genotype $\times$ environment interactions and environmental adaptation. I. Pattern analysis - Application to soya bean populations. Australian Journal of Agricultural Research 25: 59-72.

Reiner, L., 1973. Probleme der Braugerstenzüchtung in Europa. Fortschritte der Pflanzenzüchtung. Beihefte zur Zeitschrift für Pflanzenzüchtung Heft. 5; 127 pp.

Riggs, T. J., 1979. Notes on European spring barley trials. P. B.I., Cambridge, 21 pp. (mimeographed).

Riggs, T. J., 1984. Collaborative spring barley trials in Europe 1980-82. I. Analysis of grain yield. (Preprint, 32 pp.) Zeitschrift für Pflanzenzüchtung (submitted).

Russell, G., R. P. Ellis, J. Brown, G. M. Milbourn \& A. M. Hayter, 1982. The development and yield of autumn and spring sown barley in South East Scotland. Annals of Applied Biology 100: 167-178.

Saeed, M. \& C. A. Francis, 1984. Association of weather variables with genotype $\times$ environment interactions in grain sorghum. Crop Science 24: 13-16.

Sage, G. C. M., A. P. Roffey \& A. M. Stanca, 1984. Simultaneous selection of segregating two-row winter barley material in England and Italy. Euphytica 33: 187-198.

Simmonds, N. W., 1962. Variability in crop plants, its use and conservation. Biological Reviews 37: 422465.

St-Pierre, C. A., H. R. Klinck \& F. M. Gauthier, 1967. Early generation selection under different environment as it influences adaptation of barley. Canadian Journal of Plant Science 47: 507-517. 
Takahashi, R. \& S. Yasuda, 1971. Genetics of earliness and growth habit in barley. In: R. A. Nilan (Ed.), Barley genetics II, p. 388-407. W.S.U. Press, Pullman, Wash., USA, 622 pp.

Thorne, G. N., 1974. Physiology of grian yield of wheat and barley. Report Rothamsted Experimental Station for 1973, Part 2: 5-25.

Thran, P. \& S. Broekhuizen, 1965. Agroclimatic atlas of Europe. Pudoc, Wageningen and Elsevier, Amsterdam, Netherlands, 36 pp. +75 maps.

Vincent, A. \& C. Goujon, 1964. Résistance au froid chez le blé. I. Association entre vernalisation et résistance par endurcissement. Annales de l'Amélioration des Plantes 14(1): 39-56.

Vincourt, P. \& A. Gallais, 1983. Sur la recherche de critères de sélection: la régression génophénotypique. Agronomie 3(9): 827-830.

Vos, N. M. de, 1971. Interaction of temperature and photoperiods in spring cereals. In: Proceedings Eucarpia Meeting, Section Cereal Physiology, p. 85-102. INRA, Dijon, France.

Williams, W. T., 1971. Principles of clustering. Annual Review of Ecology and Systematics 2: 303-326.

Wilson, D., 1981. Breeding for morphological and physiological traits. In: K. J. Frey (Ed.), Plant breeding II, p. 233-290. The Iowa State University Press, Ames, Iowa, USA, 497 pp.

Wit, C. T. de, H. H. van Laar \& H. van Keulen, 1979. Physiological potential of crop production. In: J. Sneep \& A. J. T. Hendriksen (Eds.), Plant breeding perspectives, p. 47-81. Pudoc, Wageningen, Netherlands, $435 \mathrm{pp}$.

Wood, J. T., 1976. The use of environmental variables in the interpretation of genotype $\times$ environment interaction. Heredity $37:$ 1-7.

Wricke, G., 1962. Uber eine Methode zur Erfassung der ökologischen Streubreite in Feldversuchen. Zeitschrift für Pflanzenzüchtung 47: 92-96.

Yasuda, S., 1981. The physiology of earliness in barley. In: Barley genetics IV, p. 507-517. Edited by the Sub-Committe of the IVth International Barley Genetics Symposium. Edinburgh University Press, Edinburgh, 974 pp.

Yates, F. \& W. G. Cochran, 1938. The analysis of groups of experiments. Journal of Agricultural Science, Cambridge 28: 556-580. 